\title{
Proteolipid Protein Gene Modulates Viability and Phenotype of Neurons
}

\author{
Shayne E. M. Boucher, ${ }^{1}$ Maria A. Cypher, ${ }^{2}$ Leon R. Carlock, ${ }^{2}$ and Robert P. Skoff ${ }^{1,2}$ \\ ${ }^{1}$ Department of Anatomy and Cell Biology and ${ }^{2}$ Center for Molecular Medicine and Genetics, Wayne State University \\ School of Medicine, Detroit, Michigan 48201
}

\begin{abstract}
Overexpression or lack of expression of proteolipid protein (PLP) gene by oligodendrocytes causes axonal pathology. It is unclear whether dysfunction of the PLP gene mediates its effects directly on neurons or indirectly by abnormal formation of myelin sheaths. We performed experiments using cocultures and conditioned media (CM) to test the direct effect of PLP gene expression on neurons. Non-glial cell lines were stably transfected with PLP or DM20 (an alternate splice variant of PLP) cDNAs. Immunocytochemistry and enhanced green fluorescent protein expression showed that translated products were synthesized and inserted into the plasma membrane in proper conformation. The number of surviving dorsal root ganglion (DRG) neurons was significantly less than controls when cocultured for $5 \mathrm{~d}$ with PLP-expressing cells. The number of degenerating neurons increased in a dose-dependent manner corresponding to increasing numbers of PLP-expressing cells.
\end{abstract}

However, the number of surviving DRG neurons cocultured with DM20-expressing cells was comparable to that of controls, indicating that PLP-specific products contributed to decreased neuron survival. When DRG neurons were cultured with CM from PLPor DM20-expressing cells, significantly fewer neurons survived with CM of PLP- but not DM20-expressing cells. This suggests that secreted factors from PLP-expressing cells contribute to neuronal death. Increased neuronal death found with PLPexpressing cells cannot be attributed to density-dependent artifacts, because in each experiment the density of different cell lines was similar. This effect of CM may be mediated by a negative $\mathrm{pH}$ shift elicited from PLP but not DM20 expression. These results indicate that PLP gene products directly modulate neuron viability.

Key words: proteolipid protein; DM20; dorsal root ganglion; tubulin; myelin; cell death; oligodendroglia; glia; neuron
Myelin proteolipid protein (PLP) and DM20 are highly conserved proteins that form $50 \%$ of the proteins in CNS myelin sheaths (Lees and Brostoff, 1984; Yoshida and Colman, 1996). PLP/DM20 is thought to contribute to the compaction and stability of myelin sheaths (Boison et al., 1995; Griffiths et al., 1998a). Surprisingly, PLP/DM20 is not essential for myelin formation because PLP/DM20-deficient mice form myelin sheaths, have a nearly normal life-span, and exhibit no obvious behavioral abnormalities within the first year of life (Boison et al., 1995; Klugmann et al., 1997). In contrast, animals with mutations in the PLP gene typically exhibit dysmyelination, death of oligodendrocytes (OLs), and severely shortened life-span (Knapp et al., 1996). Transgenic mice expressing supernumerary copies of native PLP genes often exhibit a phenotype similar to mammals with PLP mutations, including a shortened life-span (Kagawa et al., 1994; Readhead et al., 1994; Anderson et al., 1998; Griffiths et al., 1998b). These studies with transgenic mice show that the absence of PLP is preferable to increased PLP gene dosage. The detrimental effects of PLP overexpression may regulate OL viability and, in turn, myelin formation. Overexpression of the PLP

Received July 26, 2001; revised Nov. 5, 2001; accepted Nov. 27, 2001.

This work was supported by National Institutes of Health-National Institute of Neurological Disorders and Stroke, the National Multiple Sclerosis Society, and the Wayne State University School of Medicine. We thank Dr. Klaus-Armin Nave for kindly providing O10 antibodies, Dr. A. Fannon for kindly providing full-length normal PLP and DM20 cDNAs, Dr. J. Adler, D. Bessert, C. Perry, and M. Cerghet for technical assistance, and Drs. I. Saluja, S. Ghandour, and J. Benjamins for critical feedback on this manuscript.

Correspondence should be addressed to Robert Skoff, Wayne State University School of Medicine, Department of Anatomy and Cell Biology, 540 East Canfield, Detroit, MI 48201. E-mail: rskoff@med.wayne.edu.

Copyright (C) 2002 Society for Neuroscience $0270-6474 / 02 / 221772-12 \$ 15.00 / 0$ gene accelerates OL cell death, whereas antisense inhibition of PLP gene expression of OLs in vitro prolongs their survival (Yang and Skoff, 1997; Cypher et al., 1999).

Recent findings suggest that the PLP gene may also regulate neuronal function. In PLP/DM20-deficient mice, degenerating axons appear within 6 weeks after birth, and motor function becomes impaired after 1 year (Boison and Stoffel, 1994; Klugmann et al., 1997). In mice with a moderate increase of PLP gene expression, axonal degeneration and demyelination begin to appear at 4 months with progressive neurological disorders emerging at $\sim 1$ year (Anderson et al., 1998). The severity of the abnormalities usually correlates with the number of PLP transgene copies. These results suggest that dysregulation of the PLP gene affects neuronal function.

It is unclear whether the neurodegeneration is caused directly by high levels of PLP gene products, indirectly by mechanical forces generated by myelin, or a combination of the two. Recent evidence indicates that myelin compaction is crucial for normal neuronal cytoskeleton and function (Witt and Brady, 2000). Short-lived shiverer mice with no myelin basic protein (MBP) display loosely spiraled myelin and altered neuronal cytoskeleton in the CNS (Readhead et al., 1987; Readhead and Hood, 1990). When additional copies of the MBP gene are reintroduced, "cured" mice display thin compact myelin, reduced axonal pathology, and nearly normal life-span (Brady et al., 1999).

We tested the hypothesis that expression of the PLP gene directly affects neuron viability by coculturing dorsal root ganglia (DRG) neurons with PLP- or DM20-expressing cell lines. Strong PLP expression by the PLP cell line and media conditioned by PLP-expressing cells reduced the numbers of DRG neurons and 
increased axonal degeneration. In contrast, strong DM20 expression by the DM20 cell line and medium conditioned by DM20expressing cells did not affect neuron viability. Conditioned media (CM) from PLP but not DM20 cells acidified the $\mathrm{pH}$ of several different culture media, suggesting that PLP alters the extracellular ionic environment. In addition, DRG neurons cultured in acidified media display a comparable decrease in neuron survival, suggesting that a negative shift in media $\mathrm{pH}$ is one factor that contributes to neuronal death in this system. PLP has been proposed, on the basis of biochemical studies and homology to pore-forming receptors, to function as an ion channel. Our results provide the first physiological evidence that PLP gene expression by non-glial cells alters the extracellular ionic environment and affects neuronal viability in a culture system.

\section{MATERIALS AND METHODS}

Tissue culture. Our culture system was a modification of a DRG neuronglia coculture system used by Wood and Bunge (Wood et al., 1980; Wood and Williams, 1984; Kleitman et al., 1998). DRG neurons have both centrally and peripherally myelinated axons in vivo and are routinely and almost exclusively used by laboratories that study glial cell function. Because DRG neurons are myelinated by oligodendrocytes, they provide an appropriate model for coculture studies. DRG neurons are easily cultured, and because these neurons would be interacting with cells transfected with PLP transgene, it was critical to use neurons that are normally exposed to CNS myelin gene expression.

Pregnant 16-17 d gestation Sprague Dawley CD strain rats (Charles River, Wilmington, MA) were housed in the Division of Laboratory Animal Resources, a federally approved animal facility. Postnatal days 1-2 (P1-2) rat pups were killed by cervical dislocation followed quickly with a bilateral pneumothorax. With the dorsal half of the spinal cord vertebrae broken away, post-mitotic dorsal root ganglia (DRG) were carefully isolated, digested with a trypsin-collagenase solution $(0.25 \%$ and $10 \mathrm{mg} / \mathrm{ml}$, respectively), rinsed with serum-containing media, and resuspended to a concentration of $25 \times 10^{4} \mathrm{cells} / \mathrm{ml}$ in DRG media (see below), and $100 \mu \mathrm{l}$ of cell suspension was plated onto sterile $12-\mathrm{mm}-$ diameter round glass coverslips coated with poly-L-lysine $(12 \mathrm{mg} / \mathrm{ml})$. After $2 \mathrm{hr}$ incubation, 24-well tissue culture dishes containing coverslips plated with DRG neurons were flooded with $0.5 \mathrm{ml}$ DRG media per well.

DRG neurons were incubated in a $5 \% \mathrm{CO}_{2}$ incubator at $37^{\circ} \mathrm{C}$ with DRG media. Unless noted otherwise, all reagents were obtained from Invitrogen (Gaithersburg, MD). DRG media consisted of F12/DMEM media (containing $15 \mathrm{mM}$ HEPES buffer to inhibit fluctuation of $\mathrm{pH}$ ) supplemented with $2 \mathrm{~mm}$ L-glutamine, $0.6 \%$ glucose, $10 \%$ fetal calf serum (FCS), 5\% horse serum (HS), $100 \mathrm{ng} / \mathrm{ml} \mathrm{2.5S} \mathrm{Nerve} \mathrm{Growth} \mathrm{Factor}$ (NGF) (Harlan Biosciences, Madison, WI), and $50 \mathrm{U} / \mathrm{ml}$ penicillin-50 $\mu \mathrm{g} / \mathrm{ml}$ streptomycin solution or $25 \mu \mathrm{g} / \mathrm{ml}$ gentamicin solution. DRG cultures underwent an anti-mitotic/mitotic cycling every day with DRG neurons cultured in normal DRG media during the day followed by an overnight culture in DRG media supplemented the first night with anti-mitotic solution of $35.7 \mathrm{~mm}$ fluorodeoxyuridine $/ 15.4 \mathrm{~mm}$ uridine (Sigma, St. Louis, MO) and then the next night with $1 \mathrm{~mm}$ cytosine $\beta$-D-arabinof uranoside $\mathrm{HCl}$ (Sigma) to reduce the number of mitotically active cells. The anti-mitotic/mitotic cycling treatment lasted for 1 week. No attempt was made to generate a completely purified population of DRG neurons, because surviving fibroblast-like cells appeared to promote survival of neurons. The number of surviving DRG neurons on each coverslip varied from experiment to experiment in the range of 100-400 neurons, although the variance within an experiment was usually $<20 \%$ of the measured value.

Transformed human embryonic kidney (HEK) 293 cell lines transfected with the PLP or DM20 transgene were used to study the cellular response of DRG neurons to PLP/DM20 gene expression. HEK293 (293) cells (Clontech, Palo Alto, CA) were derived from a transformed human embryonic kidney cell line and often used for studying expression of transfected genes (see Transformed cell lines). 293 cells were briefly rinsed, trypsinized, and resuspended in coculture media with $1.5 \%$ serum (same as DRG media except that the concentrations of FCS and HS were 1 and $0.5 \%$, respectively, and without NGF). The transformed cells were plated at a density range from 0.125 to $1.5 \times 10^{4}$ cells per well containing coverslips of DRG cells that previously underwent 1 week of anti-mitotic/ mitotic cycling treatment. The low plating density of the transfected 293 cell lines took into account the expected growth and proliferation of cells during an experiment. EGFP expression did not affect the proliferation of the transfected 293 cell lines. Culture media was changed every other day. Experiments with DRG and 293 cocultures typically lasted for 1 week. Percentages of transfected cells expressing EGFP ranged from 20 to nearly $100 \%$. When pure 293 cell lines are immunostained for tubulin, a low number of tubulin-positive particles is observed. Because tubulin-immunostained debris was not observed in DRG cultures, the tubulin antibodies are most likely binding in a nonspecific manner to the debris particles. Table 1 summarizes all of the different cell lines used for this study.

To directly assess the ability of soluble molecules generated by PLPand DM20-transfected cell lines on DRG neuron survival, we applied media conditioned by the different cell lines to cultures of DRG neurons in 24-well dishes. This experiment was identical to the coculture experiments with DRG neurons and 293 cells except that dilutions of conditioned media (CM) instead of cells were added to the wells. To prepare $\mathrm{CM}$ for the experiment, different 293 cell lines were resuspended in separate $5 \mathrm{ml}$ aliquots of coculture media to prevent intermixing of cell lines and plated in individual $25 \mathrm{~cm}^{2}$ flasks at a density to reach approximately two-thirds confluency at the time of conditioned media collection. Both DM20/EGFP and PLP/EGFP cell lines had moderate percentages (40-60\%) of EGFP-expressing cells. After $4 \mathrm{~d}$, CM from different cell lines was collected. The dilutions of CM added per set of wells tested were inversely proportional to the number of cells counted per flask, calculated on the assumption that all cells synthesize and release approximately the same amount of soluble factors. For instance, wells accepting $\mathrm{CM}$ from a flask with the lowest density of cells may receive full-strength undiluted aliquots, whereas those wells accepting CM from a flask with the higher density of cells would receive diluted aliquots. The dilutions were adjusted according to the ratio of cells counted in the flask, with the higher cell density to cells counted in the flask with the lowest cell density. Unconditioned coculture media made up the balance for wells not receiving full-strength aliquots. The wells were not changed for the duration of the experiment. At the end of the experiment, DRG neuron coverslips within the wells were immunostained for class III $\beta$-tubulin, a specific marker for neurons, and the number of tubulin-positive neurons per coverslip was counted.

For measuring $\mathrm{pH}$ of media conditioned by 293 cell lines, each cell line was grown in separate $25 \mathrm{~cm}^{2}$ flasks under three different culture conditions for 4 or $6 \mathrm{~d}$. At the end of the culture period, media was collected and allowed to equilibrate in separate, capped $15 \mathrm{ml}$ centrifuge tubes. After equilibration, the $\mathrm{pH}$ of basal media (BM) and media conditioned by 293, DM20/EGFP, and PLP/EGFP cells was measured using a standard, calibrated $\mathrm{pH}$ meter. DMEM media contained $44 \mathrm{~mm}$ bicarbonate. Coculture media contained $14.3 \mathrm{~mm}$ bicarbonate and $15 \mathrm{~mm}$ HEPES, which inhibits fluctuation of media $\mathrm{pH}$. In addition, cells from the separate flasks were trypsinized, resuspended in DMEM media with $10 \%$ serum, and counted on a hemacytometer to calculate the cell density for each cell line (see Table 2). The media $\mathrm{pH}$ experiments for transfected 293 cell lines with a cytomegalovirus (CMV) promoter were repeated at least six times. In our hands, PLP/EGFP Tet-On cells treated with $10 \mu \mathrm{g} / \mathrm{ml}$ doxycycline in passage or coculture media do not acidify the media.

To test the possibility that $\mathrm{pH}$ may modulate survival of DRG neurons, we conducted an experiment with acidified coculture media. Postnatal DRG neurons were cultured for the standard 1 week mitotic/anti-mitotic cycling before the acidified $\mathrm{pH}$ experiment was initiated. The $\mathrm{pH}$ of coculture media was adjusted with $0.1 \mathrm{~N} \mathrm{HCl}$ from basal $\mathrm{pH} 7.3$ to 6.7 , a decrease of $0.6 \mathrm{pH}$ units. The $\mathrm{pH}$ level chosen was based on results from $\mathrm{pH}$ measurement experiments. One set of DRG coverslips received basal media and a second set received acidified coculture media. After $5 \mathrm{~d}$ culture with no change of media, the $\mathrm{pH}$ of each condition was measured, the coverslips were processed for tubulin immunocytochemistry, and the number of surviving DRG neurons was counted.

Transformed cell lines. To examine the effects of PLP gene expression on neuron function, we used a 293 cell line transfected with full-length cDNAs of PLP or DM20. EGFP, PLP-EGFP, and DM20-EGFP constructs were transfected into 293 cells with ProFection, a calcium phosphate transfection kit (Promega, Madison, WI). The constructs contain a neomycin/G418 resistance cassette to select for stable transformants. Full-length normal PLP and DM20 cDNAs were kindly provided by Dr. A. Fannon (Mt. Sinai School of Medicine) for the construction of stable PLP- and DM20-expressing cell lines. For constitutive expression of PLP and DM20, the open reading frames of PLP or DM20 were inserted 

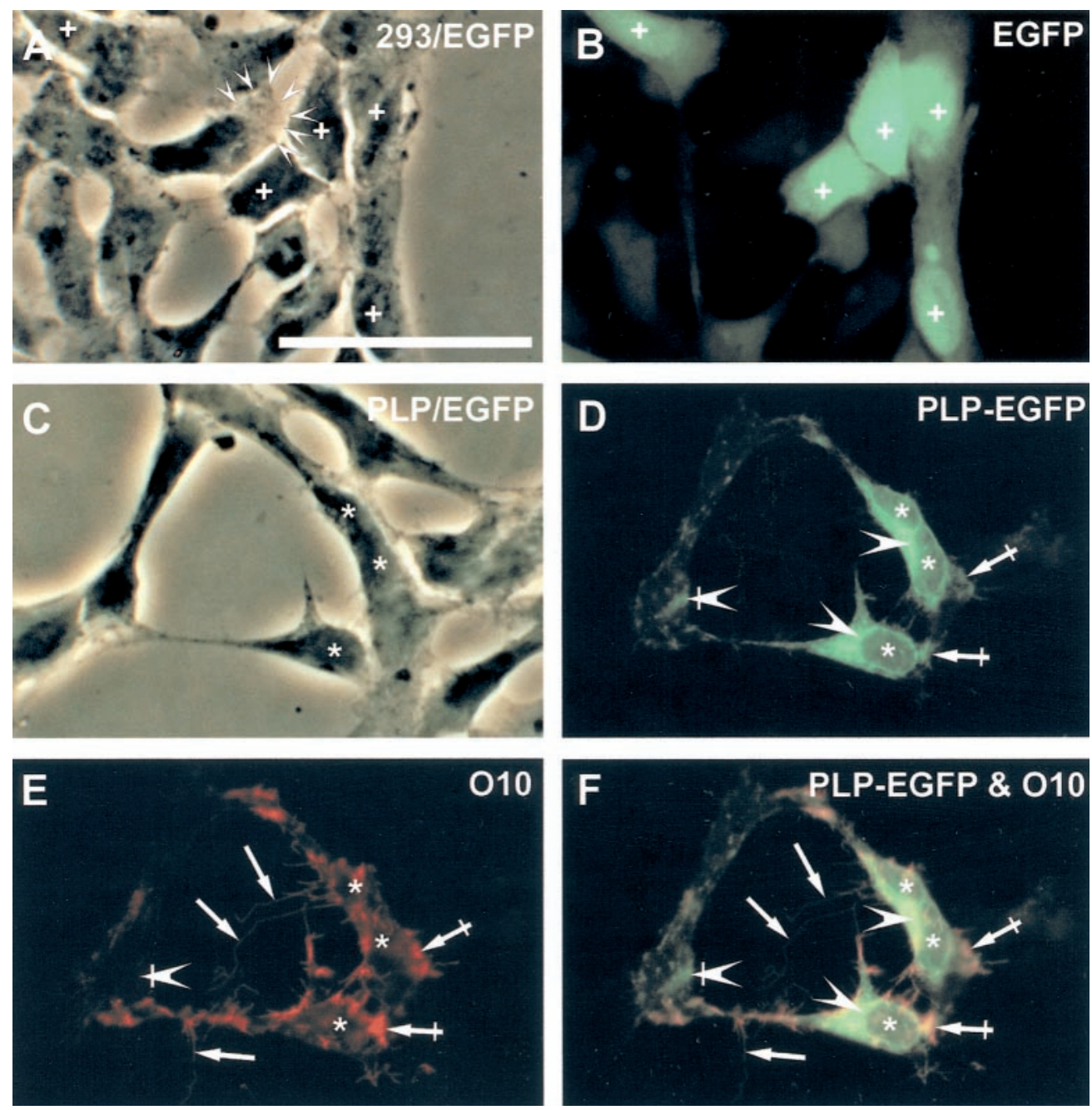

Figure 1. Morphology and EGFP localization in $5 \mathrm{~d}$ culture of 293 cells expressing only EGFP or expressing PLP-EGFP. $A$, Phase-contrast micrograph of EGFP-expressing cells cultured for $5 \mathrm{~d}$. EGFP cells display polygonal phenotype with broad, flattened processes (arrowheads). The phenotype of brightly fluorescent EGFP-expressing cells (crosses) was identical to 293 cells. $B$, Fluorescent micrograph of the same EGFP cells in $A$. EGFP fusion protein was concentrated in the nucleus with a lower amount in the cytoplasm of brightly fluorescent EGFP-expressing cells (crosses). $C$, Phase-contrast micrograph of PLP-expressing cells cultured for $5 \mathrm{~d}$. PLP-expressing cells often exhibit elongated bodies in addition to the range of phenotypes seen in 293 and EGFP cells. D, Fluorescent micrograph of the same PLP-expressing cells in C. PLP fusion protein was localized in the cytoplasm (crossed arrowhead), perinuclear areas (arrowheads), and flattened membrane sheet (crossed arrows). E, O10 live immunostaining of the same PLP-expressing cells in $C$ and $D$. O10 epitope was extensively localized on plasma membrane (crossed arrows) and long, thin processes (arrows) emanating from brightly fluorescing PLP-expressing cells (asterisks). O10 immunostaining does not colocalize with intracellular PLP fusion protein ( $D, F$, crossed arrowhead). $F$, Double-fluorescence exposure of EGFP distribution and O10 live immunostaining of the same PLP-expressing cells in $C-E$. O10 immunostaining on plasma membrane (crossed arrows) and distal processes (arrows) of PLP-expressing cells typically colocalizes with PLP fusion protein. Intracellular PLP fusion protein does not immunostain for O10 antibodies (crossed arrowhead). Scale bar, $50 \mu \mathrm{m}$.

between the CMV promoter/enhancer and EGFP sequences of pEGFP-N1 vector (Clontech). For inducible Tet-On expression of PLP, the open reading frame of PLP was inserted between the Tet-regulated CMV promoter/enhancer and EGFP sequences of pBI-EGFP vector (Clontech). For purposes of comparison and measuring relative levels of fusion protein production, we generated a stable 293 cell line with FLAG sequence, a unique octapeptide tag that does not interfere with gene expression, fused to the EGFP sequence of the pEGFP-N1 vector; immunodetection of FLAG epitope confirmed the production of intact EGFP-FLAG fusion protein (Kodak, Rochester, NY) (data not shown). Orientation of the cDNA inserts was confirmed by restriction mapping and DNA sequencing. Clones of PLP- and DM20-expressing 293 cells with the CMV promoter were obtained by isolating EGFP-expressing cells followed by a round of selective subcloning for cells with high EGFP levels. Fluorescent intensity of EGFP signal was brightest for 293/EGFP cells followed by intermediate to bright intensity in PLP/EGFP cells and intermediate intensity in DM20/EGFP cells. Western blot analysis with antibodies against EGFP confirmed the presence of PLP-EGFP and
DM20-EGFP fusion products at the appropriate molecular weights (Cypher et al., 1999).

Clones of PLP-expressing 293 cells with the Tet-On expression system (PLP/EGFP Tet-On) were obtained by acutely treating transfected cells with doxycycline and isolating EGFP-expressing cells followed by a round of selective subcloning for cells with high EGFP levels. The inducible Tet-On expression system provided a means to modulate PLP/ DM20 gene expression by adding a tetracycline derivative to induce transgene expression. For our studies, we used a concentration of 10 $\mu \mathrm{g} / \mathrm{ml}$ doxycycline to induce the Tet-On expression system that resulted in $\sim 20-40 \%$ of PLP/EGFP cells exhibiting green fluorescence signal with no discernible effect on the viability of DRG neurons. Temporal kinetics of doxycycline-treated PLP/EGFP Tet-On cells revealed a maximum level of transgene expression within $1 \mathrm{~d}$ of promoter induction, and then the level of expression decreased and stabilized at $75 \%$ of maximum level for long-term treatment (data not shown). In addition, the relative level of mRNA synthesis for a set number of EGFP-expressing cells under Tet-On promoter regulation was $\sim 15 \%$ lower than for EGFP- 


\begin{tabular}{llll}
\hline \multicolumn{4}{l}{ Table 1. Cell lines used for PLP/DM20 transgene expression studies } \\
Cell line & Host cell & Transgene insert & Promoter \\
\hline Native 293 & 293 & None & None \\
293/EGFP & 293 & EGFP & CMV \\
DM20/EGFP & 293 & DM20-EGFP & CMV \\
PLP/EGFP & 293 & PLP-EGFP & CMV \\
PLP/EGFP Tet-On & $293^{a}$ & PLP-EGFP & Tet-On system
\end{tabular}

$\overline{\text { EGFP, Enhanced green fluorescent protein; CMV, cytomegalovirus; PLP, proteo- }}$ lipid protein; DM20, alternate splice product of PLP gene.

${ }^{a} 293$ Tet-On (Clontech) stably transfected with tTA (tetracycline-controlled transactivator).

expressing cells under CMV promoter regulation. The intensity of EGFP signal in induced PLP/EGFP Tet-On cells was roughly the same as PLP/EGFP CMV cells. The combined results from studies of temporal and synthetic kinetics indicated that the inducible Tet-On system was a measurably weaker promoter than the constitutive CMV system.

Untransfected 293 cells served as control for the PLP/EGFP and DM20/EGFP cells. In some experiments, the DM20/EGFP cells were used as a transgene control for PLP/EGFP cells. Uninduced 293/PLP Tet-On cells served as control for the doxycycline-treated 293/PLP Tet-On cells. 293 cell lines were normally passaged twice per week in DMEM high-glucose media supplemented with $10 \%$ Tet System Approved Fetal Bovine Serum (Clontech) and $25 \mu \mathrm{g} / \mathrm{ml}$ gentamicin solution.

Immunocytochemistry. For immunostaining of transfected cells synthesizing PLP, undiluted supernatant from cultured O10 hybridoma cells (kindly provided by Dr. Klaus Nave, Max Planck Institute for Experimental Medicine, Gottingen, Germany) that recognize an extracellular epitope of PLP and DM20 (Jung et al., 1996) was incubated on live cells for $45 \mathrm{~min}$ at room temperature. The cells were then fixed in $4 \%$ paraformaldehyde, rinsed in PBS, and then processed for secondary antibody immunoreaction with 1:300 goat anti-mouse tetramethylrhodamine isothiocyanate (TRITC)-conjugated IgM (Kirkegaard \& Perry Laboratories, Gaithersburg, MD). For immunostaining of DRG neurons, coverslips of DRG neurons and DRG neurons cocultured with transfected cells were fixed in $4 \%$ paraformaldehyde, rinsed in PBS, and incubated in the presence of $0.125 \%$ saponin detergent with 1:250 dilution of antibodies against class III $\beta$-tubulin (clone SDL.3D10; Sigma). Class III $\beta$-tubulin is preferentially synthesized in immature and mature neurons (Lee et al., 1990; Menezes and Luskin, 1994). Next, these coverslips were processed for secondary antibody immunoreaction with 1:300 dilution of goat anti-mouse TRITC-conjugated IgG (Roche Molecular Biochemicals, Indianapolis, IN). Some coverslips were dipped in a solution of $0.0001 \%$ DAPI for $10 \mathrm{sec}$ to stain nuclei that can be visualized under fluorescent microscopy. All photomicrographs were taken with either an automatic Nikon camera system or a digital SPOT RT camera on a Leica DMIRB inverted fluorescent/phase-contrast/ differential interference contrast microscope. The total number of tubulin-positive DRG neurons per $12 \mathrm{~mm}$ coverslip was determined with the same microscope setup.

Digital laser cytometry. An attached cell analysis system (ACAS) laser cytometer workstation (Meridian Instruments, Okemos, MI) was used to compare relative levels of fluorescent intensity of tubulinimmunoreactive neurons in 1 week cocultures of DRG neurons with (1) untreated PLP/EGFP Tet-On cells and (2) doxycycline-treated PLP/ EGFP Tet-On cells. We digitally captured four images of tubulin-positive DRG neuron clusters from each coverslip with four coverslips per condition. Beginning at the center of the coverslip and moving the stage in a spiral pattern, the first four DRG clusters were imaged. DRG neurons were identified under phase-contrast light microscopy by their large, refractive cell bodies. The parameters for imaging DRG neurons were established for doxycycline-treated cells, and then the same parameters were applied to controls. Subsequently, thresholds for the images of both control and treated cells were set at the same level to remove background signals, and total fluorescent pixels for each image were quantified using ACAS software. Averages of total fluorescent pixels per condition were calculated and statistically analyzed using a Student's $t$ test.

\section{RESULTS \\ Modulation of cellular phenotype by PLP and DM20 transgenes}

Phenotypes of 293 and 293-EGFP cells were compared with DM20-EGFP and PLP-EGFP cells. Native 293 cells and 293 cells stably transfected with an EGFP transgene driven by a constitutive CMV promoter (named EGFP expressing cells) displayed a heterogeneous phenotype when visualized under phase-contrast microscopy. Both cell lines exhibited squamous and cuboidal morphologies with broad, flattened processes (Fig. 1A). Typically, 293 and EGFP-expressing cells formed clusters with neighboring cells. At higher magnification, some 293 and EGFP expressing cells displayed microvilli at their thin outer edges. In $5 \mathrm{~d}$ cultures, EGFP was more intense within the nucleus than in the cytoplasm (Fig. 1B).

Two cell lines were created using a DM20 or PLP transgene driven by a constitutive CMV promoter: (1) 293 cells stably transfected with DM20-EGFP transgene (named DM20 expressing cells) and (2) 293 cells stably transfected with PLP-EGFP transgene (named PLP expressing cells) (Table 1). Cell lines stably transfected with DM20 and PLP transgenes underwent certain phenotypic changes. DM20- and PLP-expressing cells exhibited a heterogeneous phenotype with a proportion displaying elongated cell bodies and thin, long processes (Fig. 1C). In $5 \mathrm{~d}$ cultures, the PLP fusion product was distributed throughout the cytoplasm extending from the perinuclear membrane into the processes (Fig. 1D). The PLP-transfected cell lines mimicked the distribution pattern of PLP reported by three groups examining Cos-7 and HeLa cell lines transfected with a PLP transgene (Gow et al., 1994a; Sinoway et al., 1994; Thomson et al., 1997).

As an immunological marker for PLP, the O10 antibody detects a conformationally specific extracellular loop of PLP (Jung et al., 1996). Live immunodetection of O10 antibody on $5 \mathrm{~d}$ cultures of nonpermeabilized PLP-expressing cells revealed strong immunostaining overlying the cell bodies and tips of long, distal microvilli (Fig. 1E). Live O10 immunostaining colocalized with the PLP fusion protein, indicating that the fusion protein was transported and inserted into the plasma membrane in its proper orientation (Fig. $1 F$ ). Large pools of intracellular PLP were localized around the nucleus and in processes, as indicated by the absence of colocalization with live $\mathrm{O} 10$ immunostaining (Fig. $1 F$ ). As with PLP expressing cells, live immunodetection of O10 antibody on 5 d cultures of nonpermeabilized DM20 expressing cells revealed $\mathrm{O} 10$ colocalization with DM20 fusion protein on distal microvilli, indicating transport and insertion of the DM20 fusion protein into the plasma membrane in its proper orientation (data not shown). O10 immunoreactive PLP and DM20 fusion proteins were usually found in clusters of cells expressing EGFP. O10 immunoreactivity was never observed on native 293 cells or EGFP-expressing cells (data not shown).

Although PLP and DM20 cells lines were each derived from a single colony, subsequent passage resulted in segregation of plasmid expressing fluorescent protein. This segregation produced mixed cultures containing both expressing and nonexpressing cells. Our previous studies suggest that segregation is caused partially by changes in the growth rate such that PLP-expressing cells grow slower than nonexpressing cells. In some passaged cell cultures, $>80 \%$ of the cells expressed DM20 or PLP fusion protein, whereas other passaged cell cultures had moderate percentages $(40-60 \%)$ at the time of plating. In cocultures with DRG neurons, high percentages of DM20-expressing cells were 
Figure 2. Morphology, EGFP localization, and class III $\beta$-tubulin immunostaining of DRG neurons cultured for 1 week plus an additional $5 \mathrm{~d}$ of coculture with DM20- or PLP-expressing cells. $A$, Phase-contrast micrograph of DRG neurons cultured for 1 week plus an additional $5 \mathrm{~d}$ of coculture with high percentages of DM20-expressing cells. DM20-expressing cells (crosses) display phenotypes similar to 293, EGFP-, and PLP-expressing cells (Fig. 1A,C). DRG neurons display high refractivity around somata (asterisks). B, Fluorescent micrograph of the DM20-expressing cells (crosses) and DRG neurons (asterisks) in $A$. DM20 fusion proteins (green) were localized in the perinuclear areas as well as distal regions of the plasma membrane. Brightly fluorescent tubulin immunostaining (red) was localized on the soma and axons of DRG neurons with single axons banding together with other axons to form a fascicle (arrows). Axons pass over areas of DM20expressing cells. $C$, Phase-contrast micrograph of DRG neurons cultured for 1 week plus an additional $5 \mathrm{~d}$ coculture with high percentages of PLP-
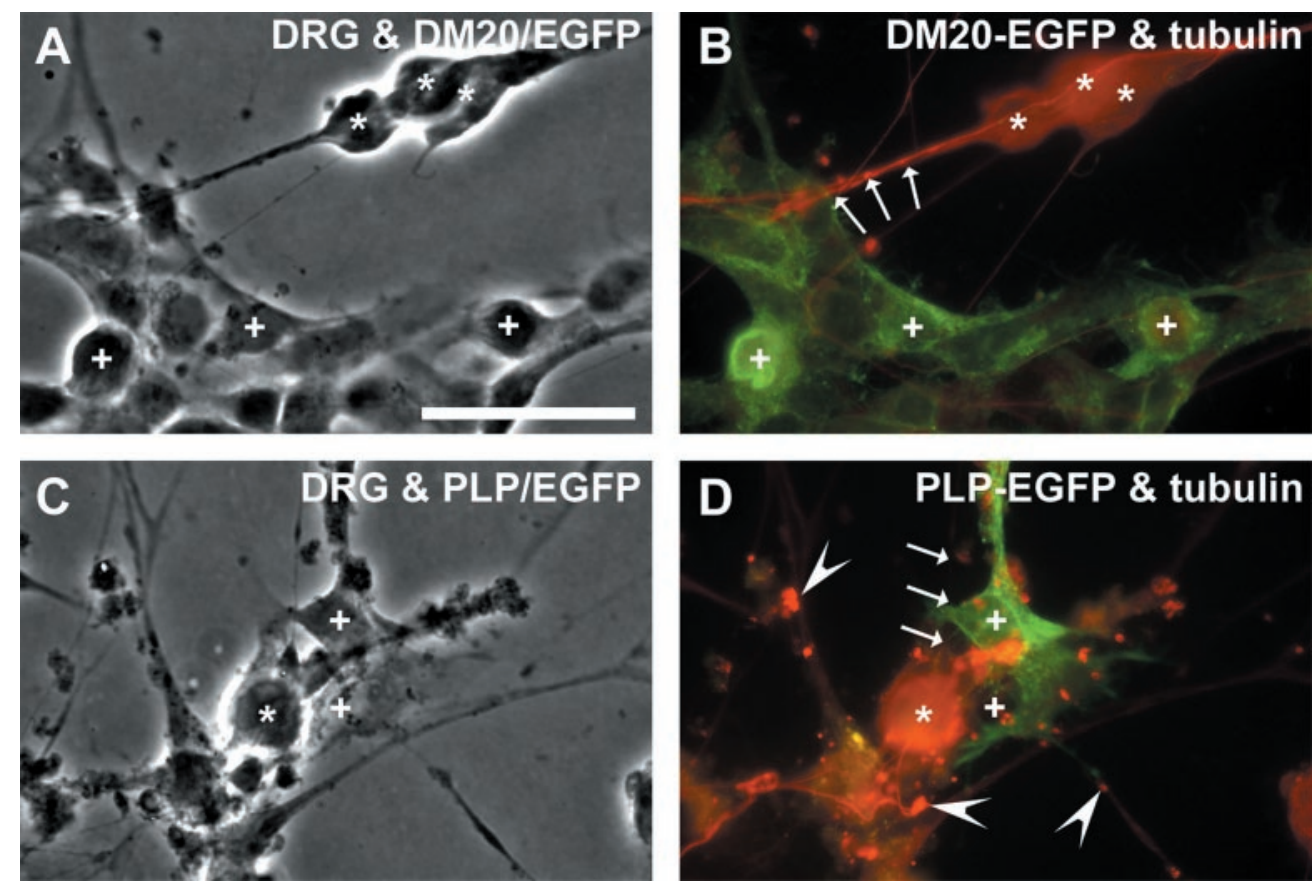

expressing cells. PLP-expressing cells (crosses) were adjacent to a refractive DRG neuron (asterisk). D, Fluorescent micrograph of the same DRG neuron (asterisk) and PLP-expressing cells (crosses) in C. Like DM20 fusion proteins, PLP fusion proteins (green) were localized in perinuclear areas and microvilli. Brightly fluorescent tubulin immunostaining (red) was localized within the somata of DRG neurons, whereas the immunostaining in axons was usually attenuated (arrows). An increased number of intense tubulin immunostained particles (arrowheads) were present in the processes and cytoplasm of DRG neurons. Scale bar, $50 \mu \mathrm{m}$.

always paired with high percentages of PLP-expressing cells. The phenotypes of DM20- and PLP-expressing cells were similar in cell cultures containing both a high percentage $(>80 \%)$ (Fig. $2 A, C$, respectively) and a moderate percentage $(40-60 \%)$ of DM20- or PLP-expressing (Fig. $1 C$ ) cells. The DM20 and PLP fusion proteins (green) were localized in perinuclear areas and outer edges of plasma membrane (Fig. $2 B, D$ ). Neurons immunostained for class III $\beta$-tubulin, a marker for immature and mature neuronal soma and processes ( red), were detected as isolated cells or in small clusters with little intermixing between the neurons and DM20- or PLP-expressing cells (Fig. $2 B$ ). Some axons passed over areas of DM20- and PLP-expressing cells (Fig. 2B,D); no conclusive evidence was found for DM20- or PLP-expressing cells wrapping around axons and forming myelin-like structures. In addition, tubulin-immunostained particles were occasionally observed when DRG neurons were cocultured with DM20expressing cells (Fig. 2B). However, there was an increased frequency of tubulin-immunoreactive particles when DRG neurons were cocultured with PLP-expressing cells (Fig. 2D). Tubulinimmunoreactive particles were rarely observed in pure cultures of DM20- and PLP-expressing cells (data not shown).

\section{PLP-expressing cells adversely affected viability of DRG neurons}

To test the hypothesis that PLP modulates neuron viability, the effects of constitutive PLP or DM20 transgene expression on DRG survival was examined using a cell-based culture assay system. For this experiment, primary cultures of enriched neonatal DRG neurons were cocultured with either DM20- or PLPexpressing cells; cultures of enriched DRG neurons or 293 cells served as controls.

DRG neurons were grown on coverslips for the first $7 \mathrm{~d}$ of the experiment under anti-mitotic/mitotic cycling conditions, and then four groups of DRG coverslips were cultured for an additional $5 \mathrm{~d}$ in coculture media with $1.5 \%$ serum (see Materials and Methods). The first group of DRG coverslips served as control, the second group of DRG coverslips was cocultured with 293 cells and also served as control, the third group of DRG coverslips was cocultured with DM20-expressing cells, and the fourth group of DRG coverslips was cocultured with PLP-expressing cells. All 293 cell lines were plated at a density of $1.25 \times 10^{3}$ cells per well, which is $20 \times$ less than the initial plating density of enriched DRG neurons. After $12 \mathrm{~d}$ of culture, the vast majority of DRG neurons in the first group showed high refractivity under phase contrast and evenly distributed tubulin immunostaining in somata and along axons (Fig. 3A,C). These DRGs appeared healthy and alive. Similarly, the number and morphology of tubulinimmunoreactive DRG neurons cocultured for 5 d with native 293 cell controls or the high percentage DM20-expressing cells were similar to DRG neurons (Fig. $4 A$ ). In contrast, DRG neurons cocultured for $5 \mathrm{~d}$ with the high percentage PLP-expressing cells showed features of degeneration as indicated by nuclear degeneration, reduced membrane refractivity, shrunken somata, punctate tubulin immunostaining, and segmented axons (Fig. $3 B, D, F)$. Quantitative analysis revealed a nearly twofold decrease in the number of surviving DRG neurons cocultured with PLP-expressing cells compared with DRG neurons or DRG neurons cocultured with 293 cells (Fig. 4A). A cell densitydependent effect of DM20- and PLP-expressing cells on neuron viability can be ruled out because the total number of DM20expressing cells was similar to 293 cells at the end of each experiment, and the total number of PLP-expressing cells was frequently less than 293 and DM20-expressing cells.

In another experiment, after 1 week of anti-mitotic/mitotic cycling conditions, DRG neurons were cultured for an additional 

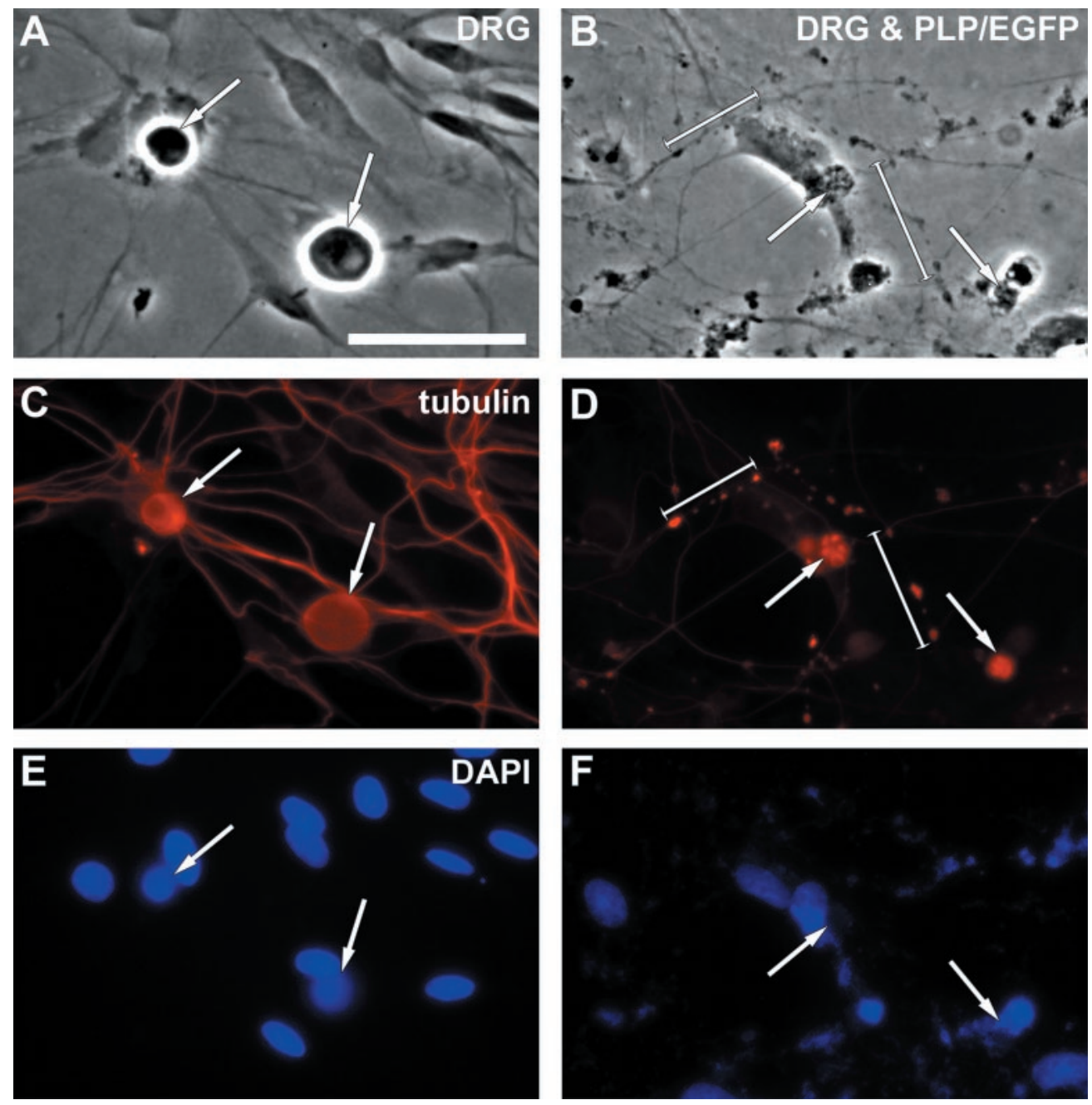

Figure 3. Morphology, class III $\beta$-tubulin immunostaining, and DAPI nuclear staining of (1) enriched DRG neurons cultured for $12 \mathrm{~d}$ and (2) DRG neurons cultured for 1 week plus an additional $5 \mathrm{~d}$ coculture with PLP-expressing cells. $A$, Phase-contrast micrograph of enriched DRG neurons (arrows) and other nonneuronal cells cultured for $12 \mathrm{~d}$. Somata of DRG neurons were spherical and refractive. $B$, Phase-contrast micrograph of DRG neurons (arrows) cultured for 1 week and then cocultured for an additional $5 \mathrm{~d}$ with moderate percentages of PLP-expressing cells. Arrows and bars identify DRG neuronal somata and processes that were degenerating $(D)$. $C$, Tubulin immunostaining (red) of the same DRG neurons in $A$. Somata (arrows) and axons were brightly and evenly immunostained. $D$, Tubulin immunostaining (red) of the same DRG neurons (arrows) in $B$. Note punctate localization of tubulin immunoreaction produced within the shrunken somata/nucleus of degenerating neurons (arrows). Axons were typically weakly immunostained compared with control; however, note intense and granular tubulin immunostaining along linear segments that corresponds to degenerating axons (bars). $E$, DAPI staining (blue) of the same DRG neurons (arrows) in $A$. Note homogeneous nuclear staining of neurons and other cell types; nuclear staining in neurons (arrows) was more diffuse because of the out-of-focus neurons compared with in-focus bed layer cells. $F$, DAPI staining (blue) of the same DRG neurons (arrows) in B. DNA was almost completely absent within degenerated neurons (arrows). Scale bar, $25 \mu \mathrm{m}$.
5 d with 293 and the moderate percentage DM20- and PLPexpressing cells. 293, DM20-, and PLP-expressing cells were plated on DRG coverslips at the same density $\left(1.25 \times 10^{3}\right.$ cells per well; $1 \times)$ as that used in the previous experiment. In addition, 293, DM20-, and PLP-expressing cells were plated at $1 / 3 \times$ and $2 / 3 \times$ density to detect dose-dependent effects. After $5 \mathrm{~d}$ of cultivation in coculture media with $1.5 \%$ serum, neurons in control DRG coverslips displayed the usual signs of high refractivity, even tubulin immunostaining and intact, spherical nuclei (Fig. $3 A, C, E)$. The total number of tubulin-positive neurons in cocultures with $1 \times 293$, DM20-, and PLP-expressing cells was the same, but the morphology of tubulin-positive neurons in cocultures with $1 \times$ PLP-expressing cells was quite different. Neurons cocultured with $1 \times$ PLP-expressing cells had very bright, punctate fluorescent immunostaining within their somata or axons (Fig. 3D). The axons visualized under phase contrast and tubulin immunostaining displayed fragmented segments with alternating regions of strong and weak tubulin immunostaining (Fig. 3B,D). Phase-contrast microscopy and 6-diamidine-2-phenylindoledihydrochloride (DAPI) staining confirmed that nuclei of neurons were undergoing various stages of degeneration (Fig. $3 B, F$ ). The number of degenerating neurons cocultured with $1 \times$ PLPexpressing cells was increased 20-, 3-, and 4-fold when compared with DRG, $1 \times 293$ and $1 \times$ DM20 controls, respectively (Fig. 4B). Even when the PLP-expressing cells were plated at $1 / 3 \times$ their normal density, the number of degenerating neurons was in- creased 11-, 1.5-, and 1.5-fold compared with DRG, 1/3× 293 and $1 / 3 \times$ DM20 controls, respectively (Fig. 4B). However, the increased number of degenerating neurons cocultured with $1 / 3 \times$ PLP-expressing cells was significant only when compared with DRG control. The number of degenerating DRG neurons in the cocultures of DRG neurons and 2/3× 293, 2/3× DM20-, and 2/3× PLP-expressing cells were not counted, but the observed intermediate degenerative effect of $2 / 3 \times \mathrm{PLP} / \mathrm{EGFP}$ cells on the neurons supports a dose-dependent trend of PLP-expressing cells on neuronal viability. The dose-dependent trend was not caused by an increased number of PLP-expressing cells because, in fact, the total number of PLP-expressing cells counted at the end of this and other experiments was often fewer than the total number of 293 and DM20-expressing cells. The slower growth rate was noticeable even in the normal passaging of PLP-expressing cells compared with native 293 and DM20-expressing cells.

In another coculture experiment, based on results with DRG neurons and PLP-expressing cells driven by Tet-On promoter (see below), we tested whether very low levels of PLP expression reduced neuronal degeneration. DRG neurons were cultured for 1 week under anti-mitotic/mitotic cycling conditions and then cultured for an additional $5 \mathrm{~d}$ with $1 / 12 \times, 1 / 6 \times$, and $2 \times$ basal density of high percentages of PLP-expressing cells. At the end of the experiment, phase-contrast microscopy, tubulin immunostaining, and DAPI staining confirmed that neurons were undergoing various stages of degeneration. The number of degenerating 
Figure 4. Quantitation of DRG neurons cocultured with 293, DM20-, and PLP-expressing cells and conditioned media experiments. Normal DRG neurons were identified by even tubulin immunostaining and a smooth, spherical cell body (Figs. $2 A, B, 3 A, C$ ). Degenerating DRG neurons were identified by bright tubulin immunostaining of particles in their perikaryon (Figs. $2 D, 3 D$ ). $A$, Average number of normal-appearing DRG neurons present in culture after $(i) 12 \mathrm{~d}$, or after $7 \mathrm{~d}$ plus an additional $5 \mathrm{~d}$ coculture with (ii) 293 cells, (iii) high percentage of DM20expressing cells, and (iv) high percentages of PLP-expressing cells. The number of normal-appearing DRG neurons was decreased nearly twofold when cocultured with PLP-expressing cells compared with being cultured alone or cocultured with 293 cells. B, Average number of degenerating DRG neurons present in culture after $(i) 12 \mathrm{~d}$, or after $7 \mathrm{~d}$ plus an additional $5 \mathrm{~d}$ coculture with (ii) $1 / 3 \times$ density 293 cells, (iii) $1 \times$ density 293 cells, (iv) $1 / 3 \times$ density moderate percentages of DM20-expressing cells, $(v) 1 \times$ density moderate percentages of DM20-expressing cells, (vi) $1 / 3 \times$ density moderate percentages of PLP-expressing cells, and (vii) $1 \times$ density moderate percentages of PLP-expressing cells. The number of degenerating DRG neurons was significantly increased for all 293 cell lines (asterisks) cocultured with DRG neurons. The coculture of (vii) DRG neurons plus $1 \times$ PLP-expressing cells displayed a 20-, 3- (cross), and 4-fold (crisscross) increase when compared with (i) DRG neurons, (iii) DRG neurons plus $1 \times 293$ cells, and $(v)$ DRG neurons plus DM20-expressing cells, respectively. Even when cocultures of (vi) DRG neurons plus $1 / 3 \times$ PLP-expressing cells were compared with control cocultures of (ii) DRG neurons plus $1 / 3 \times 293$ cells and (iv) DRG neurons plus $1 / 3 \times$ DM20-expressing cells, a trend was obvious but not significant ( $p>0.07$, two-tailed $t$ test). $C$, Average number of degenerating DRG neurons present in culture after $(i) 12 \mathrm{~d}$, or after $7 \mathrm{~d}$ plus an additional $5 \mathrm{~d}$ coculture with (ii) $1 / 12 \times$, (iii) $1 / 6 \times$, and (iv) $2 \times$ density of high percentages of PLP-expressing cells. The number of degenerating DRG neurons was significantly decreased for $1 / 12 \times$ and increased for $2 \times$ the density of PLP-expressing cells (asterisks). D, Average number of normal-appearing DRG neurons present in culture after $4 \mathrm{~d}$ with (i) basal media $(B M)$, (ii) conditioned media $(C M)$ from flask of 293 cells, (iii) CM from flask of moderate percentages of DM20-expressing cells, and (iv) CM from flask of moderate percentages of PLP-expressing cells. The number of surviving DRG neurons cultured with CM of 293 cells and DM20-expressing cells was not significantly decreased. However, the number of surviving DRG neurons cultured with CM of PLP-expressing cells was decreased $>2.5$ - (asterisk), 2.5- (cross), and 2-fold (crisscross) compared with controls, $(i)$ DRG neurons plus BM, (ii) DRG neurons plus 293 CM, and (iii) DRG neurons plus DM20/EGFP CM, respectively. For all bar graphs, ${ }^{\#+*} p<0.05$; two-tailed $t$ test.

neurons cocultured with $2 \times$ PLP-expressing cells increased by $>2.5$-fold compared with DRG neurons cultured alone, confirming that high density of PLP/EGFP is detrimental for neurons. Coculture of DRG neurons with $1 / 6 \times \mathrm{PLP} / \mathrm{EGFP}$ elicited no change in the number of degenerating neurons compared with control. In contrast, the number of degenerating neurons was significantly decreased when DRG neurons were cocultured with 1/12× PLP-expressing cells (Fig. 4C). These results confirm a dose-dependent trend of PLP-expressing cells on neuronal viability and indicate that low percentages of PLP-expressing cells reduce degeneration of DRG neurons. To verify that PLP-EGFP cells plated at $1 / 12 \times$ density expressed less PLP than $2 \times$ density, we measured the relative levels of EGFP in the two conditions. Coverslips were sampled, the total number of fluorescent pixels was counted (NIH Image, v1.62) after subtracting for background (see Materials and Methods), and the means were calculated for both conditions. We found that coverslips containing PLPexpressing cells plated at 1/12 density had nearly 14-fold less fluorescence than coverslips containing PLP-expressing cells plated at $2 \times$ density.

To test the possibility that soluble factors affect neuron viability, DRG neurons were cultured on coverslips for $4 \mathrm{~d}$ with BM or CM obtained from separate flasks of 293 cells and the moderate percentage DM20- or PLP-expressing cells grown in coculture media with $1.5 \%$ serum (see Materials and Methods). When incubated with CM obtained from flasks of PLP-expressing cells, the number of surviving DRG neurons decreased by 2.5-, 2.5-, and 2-fold compared with BM, 293 CM, and DM20 CM, respectively (Fig. 4D). This decrease was not observed with $\mathrm{CM}$ obtained from flasks of 293 or DM20-expressing cells (Fig. 4D). The $\mathrm{CM}$ was prepared on the basis of the assumption that the concentration of soluble factors present in a given volume of CM was directly proportional to the number of cells within the flask. Accordingly, cells were initially plated at slightly different densities so that when CM was collected, the final cell density would be roughly similar for the different cell lines (Table 2). We then normalized the amount of CM from the different cell lines so that the amount of CM added per well should have roughly the same concentration of solutes (see Materials and Methods) The CM was not replaced for the duration of the experiment. The results of the CM experiments reinforce the notion that strong to moderate levels of PLP gene expression were detrimental to the health of DRG neurons.

We consistently noticed in generating and carrying PLPexpressing cell lines that the media $\mathrm{pH}$ decreased after several days of cultivation in flasks or wells, but not with 293 or DM20expressing cell lines. We performed a set of experiments with 293 and moderate percentages of DM20- and PLP-expressing cells to 
Table 2. $\mathrm{pH} /$ density $\left(10^{4} \times\right.$ cells $\left./ \mathrm{ml}\right)$ measurements after $4 \mathrm{~d}$ for flasks with DMEM (high glucose) with $10 \%$ FBS, and $6 \mathrm{~d}$ for flasks with coculture media (F12/DMEM media containing $15 \mathrm{~mm}$ HEPES) with $1.5 \%$ serum or coculture media with no serum

\begin{tabular}{lllll} 
& & & & \\
\cline { 3 - 4 } Media & Bell lines & DM20/EGFP pH/density & PLP/EGFP pH/density \\
\cline { 3 - 5 } DMEM + 10\% FBS & 8.01 & $7.86 / 61$ & $7.80 / 54$ & $7.36 / 62$ \\
Coculture media + 1.5\% serum & 7.69 & $7.17 / 44$ & $7.22 / 20$ & $7.00 / 25$ \\
Coculture media + no serum & 7.43 & $7.35 / 16$ & $7.42 / 19$ & $7.12 / 24$ \\
\hline
\end{tabular}

The observed $\mathrm{pH}$ changes were reproducible in six different experiments.

discern differences in media $\mathrm{pH}$ between the different cell lines. The media $\mathrm{pH}$ and cell density for the stably transfected 293 cell lines were measured under three different culture conditions. Compared with 293 cells used as control, PLP-expressing cells reduced the $\mathrm{pH}$ of media ranging from 0.17 to $0.50 \mathrm{U}$, whereas DM20-expressing cells typically displayed $\mathrm{pH}$ levels similar to control, ranging from -0.06 to $+0.07 \mathrm{U}$. This decrease in $\mathrm{pH}$ levels by PLP-expressing cells took place despite using F12/ DMEM media containing $15 \mathrm{mM}$ HEPES, a moderately strong zwitterionic buffer. Cell density of PLP-expressing cells was similar to or less than native 293 cell control and DM20-expressing cells. For the first condition, 293 cells and DM20- and PLPexpressing cells were plated in flasks at a density to reach approximately two-thirds confluency after $4 \mathrm{~d}$ incubation in DMEM passage media with $10 \%$ FBS. In the other two conditions, 293 cells and DM20- and PLP-expressing cells were plated in flasks at the same initial density and cultured for $6 \mathrm{~d}$ in either coculture media with $1.5 \%$ FCS or coculture media with no serum (see Materials and Methods). The $\mathrm{pH}$ of fresh culture media for each condition was measured and served as basal media (Table 2). No strong change was measured between the $\mathrm{pH}$ of basal media and native 293 cells or DM20-expressing cells except when native 293 and DM20-expressing cells were cultured in coculture media with $1.5 \%$ FCS. Examination of live cultures revealed no obvious qualitative differences in the number of detached, rounded cells between the different cell lines, indicating that the number of dying or dead cells present within each flask did not differ noticeably. Table 2 summarizes the media $\mathrm{pH}$ and cell density measurements for the experiments.

Because neuron viability may be $\mathrm{pH}$ dependent, we tested the ability of cultured DRG neurons to survive in acidified media. Similar to coculture experiments, DRG neurons were cultured for 1 week under anti-mitotic/mitotic cycle conditions followed by an additional $5 \mathrm{~d}$ either in basal media at $\mathrm{pH} 7.3$ or in acidified media at pH 6.7, with no media changes for the duration of the experiment. The selected $\mathrm{pH}$ of acidified media was based on previous observations during which the $\mathrm{pH}$ of passage media conditioned by high percentages of PLP-expressing cells could reach as low as 6.79. After termination of the experiment, basal and acidified media were collected separately, and $\mathrm{pH}$ levels were measured. The presence of $\mathrm{CO}_{2}$ gas in the incubators shifted $\mathrm{pH}$ from 7.30 to 7.56 for basal media and from 6.70 to $7.22 \mathrm{pH}$ for acidified media. Thus, DRG neurons were exposed to the initial, acidic $\mathrm{pH}$ for only a limited period as the media $\mathrm{pH}$ gradually became more basic. For DRG neurons cultured in acidified media, the cells displayed increased levels of tubulin-immunoreactive particles similar to the particles observed in cocultures of DRG neurons and PLP-expressing cells. No such tubulin-immunoreactive particles were observed on DRG coverslips cultured in basal media. The number of surviving DRG neurons treated with acidified media decreased by more than twofold compared with neurons cultured in basal media (data not shown). These results confirm findings from coculture and flask $\mathrm{pH}$ experiments.

\section{Inducible PLP transgene expression promoted growth and survival of DRG neurons}

To further evaluate the effects of PLP gene expression on survival of DRG neurons, we used a 293 cell line transfected with a PLP-EGFP transgene driven by an inducible Tet-On system (Tet-On PLP-expressing cells) (Table 1). Cultures of enriched DRG neurons or untreated Tet-On PLP cells served as controls for the doxycycline-treated DRG neurons and Tet-On PLPexpressing cells, respectively.

After 1 week of anti-mitotic/mitotic cycling followed by an additional 1 week cultivation, enriched DRG neuron cultures were similar in appearance to our other control DRG experiments (for example, see Fig. $3 C$ ). DRG neurons were often observed as individual cells or, with less frequency, in small clusters of two to three neurons. When DRG neurons were cocultured for an additional week after anti-mitotic/mitotic treatment with untreated Tet-On PLP cells, DRG neurons exhibited a small increase in their size and total number of DRG neuron clusters (Fig. 5A). Despite the small increase in the size and number of clusters in these cocultures, the number of surviving DRG neurons was similar to enriched DRG neurons or enriched DRGs treated with doxycycline (Fig. 5D). DRG neurons cocultured for 1 week with doxycycline-induced Tet-On PLP cells showed a significant 1.5 -fold increase in the number of surviving DRG neurons compared with enriched DRG neuron cultures or doxycycline-treated DRG neuron controls (Fig. 5D). The frequency of moderate- as well as large-sized (five or more) clusters also increased (Fig. 5B,C). In these experiments, doxycycline was applied at $10 \mu \mathrm{g} / \mathrm{ml}$ to induce a significant level of PLP expression (20-40\% EGFP-expressing cells) without killing neurons (see Materials and Methods). Higher concentrations $(100 \mu \mathrm{g} / \mathrm{ml})$ of doxycycline applied directly to enriched DRG cultures caused major neuronal death. DRG neurons cocultured with doxycycline-treated Tet-On PLP cells never displayed the level of punctate tubulin immunostaining seen in cocultures of DRG neurons and PLP/EGFP cells (Table 1). In addition, we did not observe an acidic shift of media $\mathrm{pH}$ by PLP/EGFP Tet-On cells, unlike PLP/EGFP cells. The difference in survival between using the Tet-On and CMV constitutive cell lines may be attributable to differences in total amounts of PLP expressed by the two cell lines. In flasking experiments, we compared the levels of PLP fusion protein induced by the Tet-On system and constitutive CMV promoter. We found by using quantitative densitometry of Western blots that the maximal induction of PLP with the Tet-On system was less than one-half that of the CMV promoter. The amount of PLP generated by the Tet-On system in our coverslip experiments was probably much less than $50 \%$ because the 
Figure 5. Morphology and survival of DRG neurons cocultured for 1 week with untreated and doxycycline-treated Tet-On PLP cells. A, Combined fluorescent and differential interference contrast photomicrograph of tubulin-immunoreactive DRG neurons cocultured for 1 week with untreated Tet-On PLP cell line. Neurons form small clusters and send out linear processes. $B$, Fluorescent micrograph of two clusters of tubulinimmunoreactive DRG neurons cocultured for 1 week with doxycyclineinduced Tet-On PLP cells. Frequently, interconnecting axons join clusters of DRG neurons over long distances $(>250$ $\mu \mathrm{m})$, have a thicker fascicle bundle, and display increased intensity of tubulin immunostaining compared with DRG neuron control. $C$, Tubulin-immunoreactive DRG neurons (red) cocultured for 1 week with Tet-On PLP cells (green). Note larger DRG neuron clusters and increased number of axons compared with DRG neuron control. Some of the DRG neurons in the cluster cannot be seen in this photomicrograph because of out-of-plane focus of distal regions of the
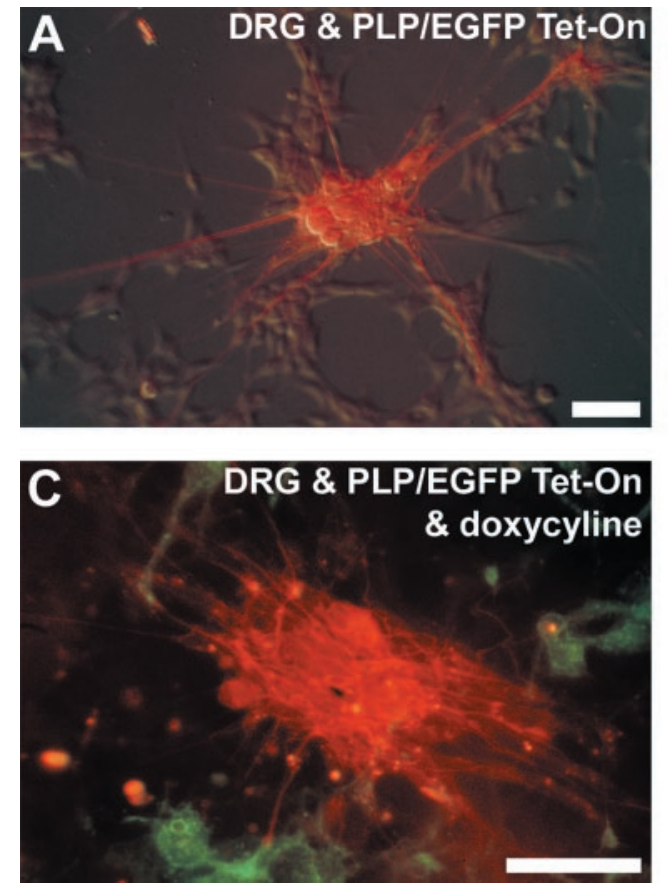

DRG \& PLP/EGFP Tet-On
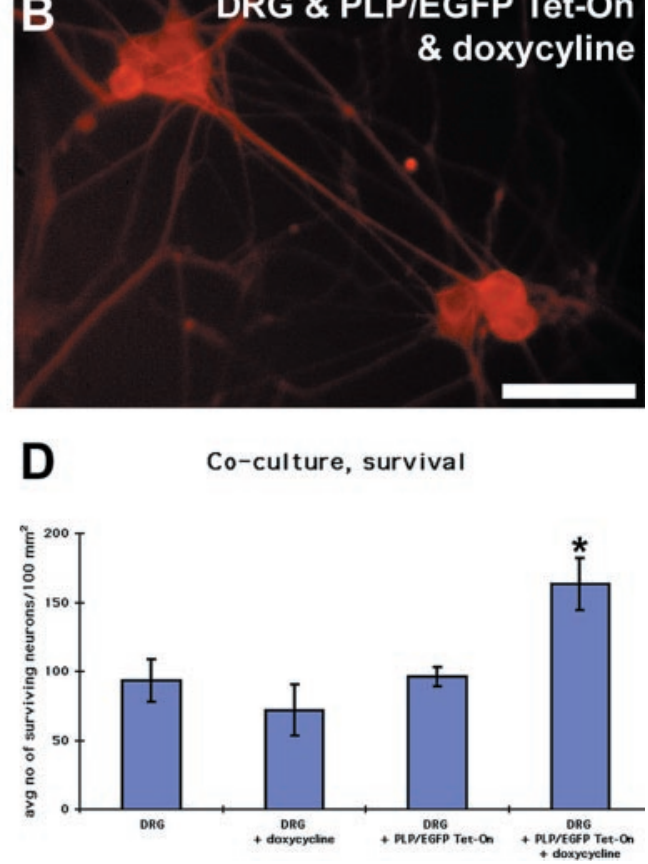
three-dimensional structure. Tubulin-

immunostained DRG neurons in Figure 5, $B$ and $C$, were from separate experiments. $D$, Average number of normal DRG neurons cultured for 1 week with or without doxycycline treatment and Tet-On PLP cells with or without doxycycline. The number of surviving DRG neurons was significantly increased in the presence of doxycycline-treated Tet-On PLP cells compared with DRG neuron controls. ${ }^{*} p<0.05$; two-tailed $t$ test. Scale bar, $50 \mu \mathrm{m}$.

Tet-On cells gradually lost maximal fluorescence after $24 \mathrm{hr}$ in culture.

DRG neurons displayed no strong preference to be adjacent to or intermix with doxycycline-treated Tet-On PLP cells (Fig. 5C). Expression of the PLP transgene in doxycycline-induced Tet-On PLP cells modulates axonal morphology of DRG neurons. Cocultures of DRG neurons with non-doxycycline-treated Tet-On PLP cells revealed a detectable increase in the level of axonal fasciculation and tubulin immunostaining compared with DRG neuron control (Fig. 5A). However, when DRG neurons were cocultured with doxycycline-treated Tet-On PLP cells, they displayed enhanced axonal fasciculation, augmented tubulin immunostaining, and an increased number of neuronal clusters (Fig. $5 B, C)$. Laser confocal sampling of the same DRG neurons examined in Figure $5 D$ revealed a relative increase in the intensity of tubulin immunostaining in somas and processes of DRG neurons cocultured with doxycycline-treated Tet-On PLP-expressing cells compared with untreated Tet-On PLP cells (Fig. 6A, $B$ ) (see Materials and Methods). Calculating the mean total number of fluorescent pixels for each condition, there was a twofold increase in total number of fluorescent pixels for tubulin-immunostained DRG neurons cocultured with doxycycline-treated Tet-On PLP cells compared with untreated Tet-On PLP cells (Fig. 6C). This result highlighted the increase in fasciculation and thickening of axons when DRG neurons were cocultured with doxycyclinetreated Tet-On PLP cells.

\section{DISCUSSION}

Many naturally occurring and man-made mutations of the PLP gene exhibit axonal abnormalities in addition to myelin defects. Axonal degeneration of centrally projecting DRG neurons is found in transgenic mice, even when overexpression of the normal PLP gene is twofold. Deletion of the PLP gene in "knock-out" mice also produces axonal deficits of DRGs (Boison and Stoffel,
1994; Klugmann et al., 1997). Point mutations of PLP gene, as in jimpy, exhibit perturbation of retinal ganglion axonal function (Nixon, 1982). These phenotypes reveal two properties of PLP gene expression: it is required for normal neuronal function, and the levels of PLP/DM20 must be tightly regulated. It is unclear whether expression of PLP gene products directly causes the neuronal abnormalities or whether alterations in thickness and compaction of myelin sheaths associated with PLP mutations secondarily affect neuronal viability (Bjartmar et al., 1999). To determine whether PLP and/or DM20 proteins directly affect neuronal viability, we used non-glial cell lines in which PLP or DM20 was constitutively expressed or induced with drugs, and then cultured these cells with neurons. PLP and DM20 cDNAs were fused to EGFP to visualize insertion of PLP and DM20 into the plasma membrane and the level of expression. Live immunostaining with $\mathrm{O} 10$ antibody, a conformationally sensitive antibody against PLP/DM20 (Jung et al., 1996), showed that the plasma membrane of both PLP- and DM20-expressing cells stained similarly and with visibly equal intensity. Homogenates prepared from PLP-EGFP and DM20-EGFP cell lines were probed with EGFP antibodies, and they showed the correct molecular weights for the combined proteins (data not shown). The percentages of 293 stably transfected cells that expressed PLP or DM20 fusion protein were not noticeably different in each experiment. Therefore, differences in survival of neurons cocultured with PLP or DM20 constitutively expressing cells cannot be attributed to differences in insertion of two different isoforms into the membrane or to differences in percentages of cells expressing DM20 and PLP. Because cell density may affect the amount of secreted molecules (especially when cells become confluent), experiments were terminated before different expressing cell lines reached confluency. Quantification of cell numbers of different cell lines at the end of each experiment were also similar. Toxicity of PLP/ 

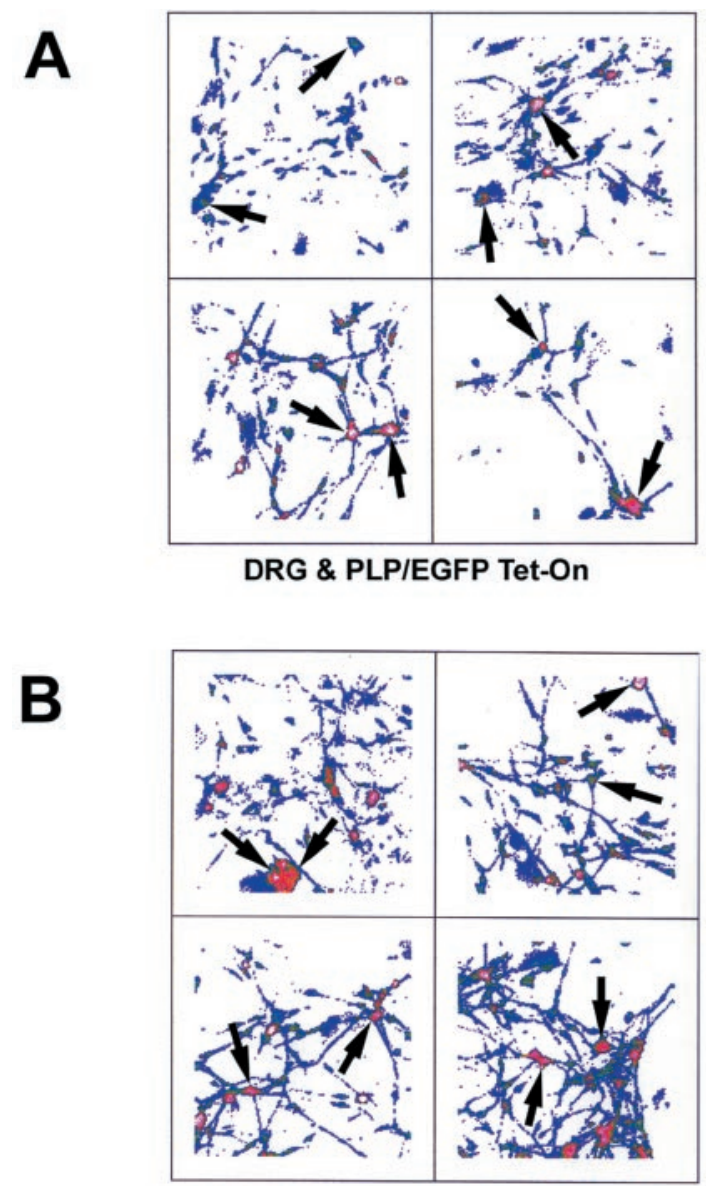

DRG \& PLPIEGFP Tet-On \& doxycycline
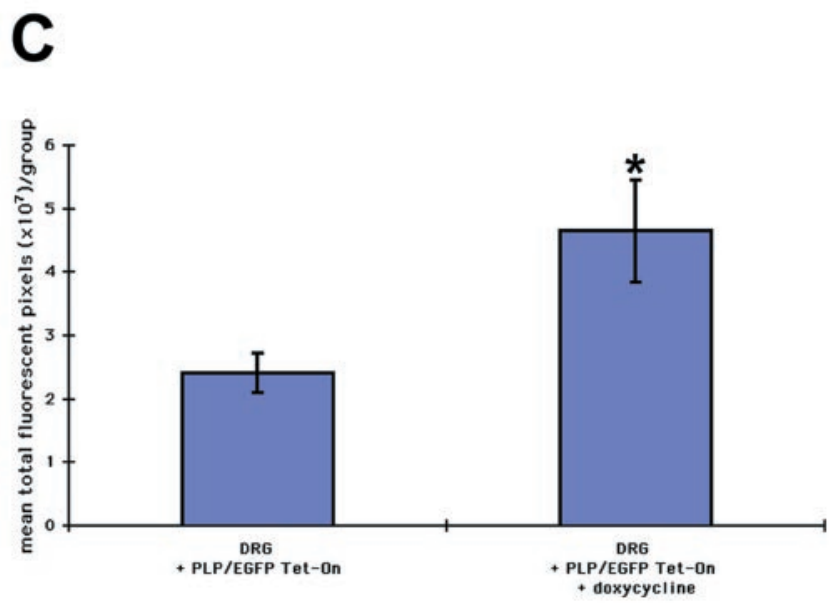

Figure 6. Relative levels of class III $\beta$-tubulin in DRG neurons cocultured for 1 week with or without doxycycline-treated Tet-On PLP cells. All images and data in Figure 6 were collected from the same experiment described in Figure 5D. Images were captured on a confocal laser cytometer workstation at a setting so that the maximum fluorescent pixels were not oversaturated. All images were then processed at a threshold setting that eliminated nonspecific tubulin immunostaining and rhodamine background staining. The color range for Figure 6, $A$ and $B$, is white for the highest level of fluorescence followed by red, green, and light blue for lowest level of fluorescence. $A$, Four fluorescent digital images of tubulin-positive neurons (arrows) and processes cocultured for 1 week with untreated Tet-On PLP cells. B, Digital images of tubulin-positive neurons (arrows) and processes cocultured for 1 week with doxycyclinetreated Tet-On PLP cells. $C$, Mean total immunofluorescent pixels of tubulin-immunoreactive DRG neurons cocultured for 1 week with or
DM20 gene products to the transfected cells should be mentioned because elevated levels of PLP and/or DM20 are often toxic to transfected cells and OLs (Kagawa et al., 1994; Cypher et al., 1999). The phase brightness and number of floaters of PLPexpressing cells were no different from DM20-expressing or 293 cells at the termination of the coculture and flasking experiments.

When neurons were cocultured with high percentages of PLPexpressing cells driven by the CMV promoter, the number of tubulin+ neurons was decreased two times compared with DRG neurons grown alone, with 293 cells, or with DM20-expressing cells. In other coculture experiments, in which the percentage of PLP-expressing cells was roughly half that of the high expressers, the total number of neurons cocultured with PLP-expressing cells was the same at the end of the experiments. However, degenerating neurons were numerous, as evidenced by aggregates of $\beta$-tubulin immunostaining in their somata and axons. Costaining with DAPI confirmed their degeneration because nuclei were shrunken or disintegrated. To determine density-dependent effects, different cell lines were plated at lower and lower densities in addition to our routine density. The number of degenerating neurons cocultured with PLP-expressing cells at one-third our routine density was noticeably increased compared with different controls. However, plating at 1/12 our routine density, PLPexpressing cells led to fewer degenerating neurons. These experiments demonstrate that high expression of PLP has a negative effect on neuronal survival, but it is unclear whether the increased degeneration is mediated directly by cell-cell contact or indirectly by secreted factors. To test the possibility that secreted factors modulate neuron survival, we demonstrated that application of CM from PLP significantly decreased the viability of neurons compared with 293 control cells and DM20-expressing cells.

Increased degeneration of neurons in media conditioned by PLP-expressing cells argues strongly for the role of soluble factors acting in a paracrine manner. However, it is unclear whether PLP itself or other factors are secreted into the medium. Interestingly, addition of purified PLP or addition of synthetic PLP peptides in nanomolar concentrations to cultured OLs increased the number of OLs (Ikenaka et al., 1992; Nakao et al., 1995; Yamada et al., 1999). Moderately higher concentrations of purified PLP caused a slight decrease, but whether higher concentrations led to further loss of OLs was not reported. Immunoprecipitation of CM from PLP/DM20-producing cells (Nakao et al., 1995) and CM from our PLP-secreting cells blotted for PLP (data not shown) failed to detect any PLP fragments.

The negative effect of PLP gene expression on neurons and OLs may not be caused by secretion of PLP or DM20 peptides but may alter the transport and exocytosis of molecules and ions not derived from PLP. Numerous classical and recent studies using different techniques provide indirect evidence that PLP isomers aggregate to form membrane pore proteins that allow unidirectional or bidirectional transfer of ions (protons, sodium, and potassium) (Ting-Beall et al., 1979; Helynck et al., 1983; de Cózar et al., 1987; Kitagawa et al., 1993). This theory may explain

without doxycycline-treated Tet-On PLP cells. The mean total of immunofluorescent pixels for DRG neurons grown in the presence of doxycycline-treated Tet-On PLP cells was significantly increased compared with those grown in the presence of untreated Tet-On PLP cells. See Materials and Methods for quantitation of image data. ${ }^{*} p<0.05$; two-tailed $t$ test. 
our observations that expression of PLP gene products acidified the extracellular $\mathrm{pH}$ of $\mathrm{CM}$. The reduction in $\mathrm{pH}$ (as much as 0.5 $\mathrm{U})$ by PLP-expressing cells occurred using three different culture media. The decrease in extracellular $\mathrm{pH}$ by PLP-expressing cells was not cell density-dependent because the number of 293 cells expressing PLP fusion protein was similar to or lower than the number of cells in control lines at the end of the experiments. Increased numbers of floating cells were not found in the PLP cell line at the time $\mathrm{CM}$ was collected. Alteration of $\mathrm{pH}$ by abnormal PLP expression has been reported previously for jimpy mice (mice with a PLP mutation). Jimpy glia exhibit abnormal $\mathrm{K}^{+}$ metabolism (Hertz et al., 1980), and intracellular $\mathrm{pH}$ was increased in glial cultures (Knapp et al., 1990). We found that simply lowering the media $\mathrm{pH}$ in DRG cultures caused increased neuronal degeneration, suggesting that acidic $\mathrm{pH}$ in and of itself causes increased neuronal degeneration. Interestingly, $\mathrm{pH}$ at the end of these DRG experiments shifted from 6.70 to 7.22 , suggesting a gradual compensation for the acidic $\mathrm{pH}$. In contrast, cells expressing PLP fusion protein drove $\mathrm{pH}$ toward the acidic side despite the presence of moderately strong buffers. Whether extracellular ionic environment of the nervous system is altered in PLP mutants is unknown, but small differences in $\mathrm{pH}$ of the magnitude found in the PLP-expressing cell line are associated with seizures (Syková and Svoboda, 1990; Xiong and Stringer, 2000), a neurological deficit observed in many PLP mutants.

Expression of DM20 protein has been proposed to facilitate the transport of PLP and possibly other molecules to the plasma membrane (Gow and Lazzarini, 1996). Newly identified somalrestricted PLP/DM20 gene products (Bongarzone et al., 1999) have also been proposed as components of the vesicular trafficking system because these gene products colocalize with clathrincoated and syntaxin 6-containing vesicles (Campagnoni and Skoff, 2001). Conversely, overloading of native or aberrant PLP products within the protein trafficking system may retard transport and ultimately induce cell death and release of toxic molecules (Gow et al., 1994b; Pahl and Baeuerle, 1997; AlvesRodrigues et al., 1998; Anderson et al., 1998). Either increased secretion of toxic molecules into the extracellular space or retardation of molecular transport by the PLP-secreting cells may also be mechanisms that modulate neuronal viability.

Although strong expression of the PLP gene using the CMV promoter caused increased degeneration, modest expression with the Tet-On system led to increased survival of neurons. Because the 293 cells used to generate constitutive- and inducibleexpressing cell lines were from the same cellular background, it is unlikely that intrinsic properties of 293 cells were responsible for the opposing effects. Different factors, including decreased expression of PLP, changes in synthesis and transport of PLP and other molecules, and induction of different molecules by the Tet-On system might have caused increased survival of neurons using the Tet-On system. Although our results are difficult to explain mechanistically, they support in vivo transgenic and human studies which show that PLP gene expression is essential for long-term maintenance of neuronal phenotype but an overabundance quickly causes neurodegeneration.

We consistently found that DM20 gene expression, either in coculture experiments or with the addition of CM from DM20expressing cells, had no significant effect on neuron viability. This finding is consistent with animal studies which show that DM20 gene overexpression, compared with PLP overexpression, has a negligible effect on neuronal viability. Transgenic mice with two to four extra copies of DM20 transgene along with wild-type PLP gene lacked neurological deficits and had a normal life-span (Johnson et al., 1995), and even mice with 17 copies of DM20 transgene behaved normally and had a normal life-span. Transgenic knock-in mice that express DM20 but not PLP displayed abnormal myelin periodicity, axonal degeneration after 6 months, and behavioral deficits after 1 year (Stecca et al., 2000). These mice show that overexpression of DM20 did not cause the same degree of neuropathy as transgenics overexpressing the PLP gene. PLP has a 35 amino acid sequence located within the intracellular loop that is missing in DM20. PLP, but not DM20, coprecipitates with inositol hexakisphosphate, and it is proposed that PLP functions as a signaling molecule (Yamaguchi et al., 1996).

Our results indicate that expression of the PLP gene by nonglial cells modulates the viability of neurons, possibly via secreted molecules and alteration of $\mathrm{pH}$. Although abnormal myelin sheath formation can contribute to axonal loss (Robertson et al., 1997), products of PLP gene expression are directly capable of altering neuronal viability. "Axonal transections" and neuronal atrophy are now recognized as important players in PelizaeausMerzbacher disease and multiple sclerosis (Griffiths et al., 1998a; Snipes and Orfali, 1998; Bjartmar et al., 1999). Our studies suggest that abnormal expression of PLP gene may directly affect axonal viability.

\section{REFERENCES}

Alves-Rodrigues A, Gregori L, Figueiredo-Pereira ME (1998) Ubiquitin, cellular inclusions and their role in neurodegeneration. Trends Neurosci 21:516-520.

Anderson TJ, Schneider A, Barrie JA, Klugmann M, McCulloch MC, Kirkham D, Kyriakides E, Nave K-A, Griffiths IR (1998) Late-onset neurodegeneration in mice with increased dosage of the proteolipid protein gene. J Comp Neurol 394:506-519.

Bjartmar C, Yin X, Trapp BD (1999) Axonal pathology in myelin disorders. J Neurocytol 28:383-395.

Boison D, Stoffel W (1994) Disruption of the compacted myelin sheath of axons of the central nervous system in proteolipid protein-deficient mice. Proc Natl Acad Sci USA 91:11709-11713.

Boison D, Büssow H, D’Urso D, Müller H-W, Stoffel W (1995) Adhesive properties of proteolipid protein are responsible for the compaction of CNS myelin sheaths. J Neurosci 15:5502-5513.

Bongarzone ER, Campagnoni CW, Kampf K, Jacobs EC, Handley VW, Schonmann V, Campagnoni AT (1999) Identification of a new exon in the myelin proteolipid protein gene encoding novel protein isoforms that are restricted to the somata of oligodendrocytes and neurons. J Neurosci 19:8349-8357.

Brady ST, Witt AS, Kirkpatrick LL, de Waegh SM, Readhead C, Tu P-H, Lee VM-Y (1999) Formation of compact myelin is required for maturation of the axonal cytoskeleton. J Neurosci 19:7278-7288.

Campagnoni AT, Skoff RP (2001) The pathobiology of myelin mutants reveals novel biological functions of the MBP and PLP genes. Brain Pathol 11:74-91.

Cypher MA, Perry C, Nguyen M, Skoff R, Carlock L (1999) Protein processing and cell death in transfected and stable cell lines expressing normal or mutant PLP/DM20 proteins. J Neurochem 72:S8.

de Cózar M, Lucas M, Monreal J (1987) Ionophoric properties of the proteolipid apoprotein from bovine brain myelin. Biochem Int 14:833-841.

Gow A, Lazzarini RA (1996) A cellular mechanism governing the severity of Pelizaeus-Merzbacher disease. Nat Genet 13:422-428.

Gow A, Friedrich VL, Lazzarini RA (1994a) Intracellular transport and sorting of the oligodendrocyte transmembrane proteolipid protein. J Neurosci Res 37:563-573.

Gow A, Friedrich VL, Lazzarini RA (1994b) Many naturally occurring mutations of myelin proteolipid protein impair its intracellular transport. J Neurosci Res 37:574-583.

Griffiths I, Klugmann M, Anderson T, Thomson C, Vouyiouklis D, Nave K-A (1998a) Current concepts of PLP and its role in the nervous system. Microsc Res Tech 41:344-358.

Griffiths I, Klugmann M, Anderson T, Yool D, Thomson C, Schwab MH, Schneider A, Zimmermann F, McCulloch M, Nadon N, Nave K-A (1998b) Axonal swellings and degeneration in mice lacking the major proteolipid of myelin. Science 280:1610-1613.

Helynck G, Bang L, Nussbaum J-L, Picken D, Skalidis G, Trifilieff E, Van Dorsselaer A, Seta P, Sandeaux R, Gavach C, Heitz F, Simon D, Spach 
G (1983) Brain proteolipids: isolation, purification and effect on ionic permeability of membranes. Eur J Biochem 133:689-695.

Hertz L, Chaban G, Hertz E (1980) Abnormal metabolic response to excess potassium in astrocytes from the Jimpy mouse, a convulsing neurological mutant. Brain Res 181:482-487.

Ikenaka K, Kagawa T, Mikoshiba K (1992) Selective expression of DM20, an alternatively sliced myelin proteolipid protein gene product, in developing nervous system and in nonglial cells. J Neurochem 58:2248-2253.

Johnson RS, Roder JC, Riordan JR (1995) Over-expression of the DM-20 myelin proteolipid causes central nervous system demyelination in transgenic mice. J Neurochem 64:967-976.

Jung M, Sommer I, Schachner M, Nave K-A (1996) Monoclonal antibody O10 defines a conformationally sensitive cell-surface epitope of proteolipid protein (PLP): evidence that PLP misfolding underlies dysmyelination in mutant mice. J Neurosci 16:7920-7929.

Kagawa T, Ikenaka K, Inoue Y, Kuriyama S, Tsujii T, Nakao J, Nakajima K, Aruga J, Okano H, Mikoshiba K (1994) Glial cell degeneration and hypomyelination caused by overexpression of myelin proteolipid protein gene. Neuron 13:427-442.

Kitagawa K, Sinoway MP, Yang C, Gould RM, Colman DR (1993) A proteolipid protein gene family: expression in sharks and rays and possible evolution from an ancestral gene encoding a pore-forming polypeptide. Neuron 11:433-448.

Kleitman N, Wood PM, Bunge RP (1998) Tissue culture methods for the study of myelination. In: Culturing nerve cells, Ed 2 (Banker G, Goslin $\mathrm{K}$, eds), pp 545-594. Cambridge, MA: MIT.

Klugmann M, Schwab MH, Pühlhofer A, Schneider A, Zimmermann F, Griffiths IR, Nave K-A (1997) Assembly of CNS myelin in the absence of proteolipid protein. Neuron 18:59-70.

Knapp PE, Booth CS, Skoff RP (1990) Intracellular pH is increased in Jimpy glia: in vitro measurements in single cells. Ann NY Acad Sci 605:382-383.

Knapp PE, Benjamins JA, Skoff RP (1996) Epigenetic factors upregulate expression of myelin proteins in the dysmyelinating jimpy mutant mouse. J Neurobiol 29:138-150.

Lee MK, Tuttle JB, Rebhun LI, Cleveland DW, Frankfurther A (1990) The expression and posttranslational modification of a neuron-specific $\beta$-tubulin isotype during chick embryogenesis. Cell Motil Cytoskeleton $17: 118-132$.

Lees M, Brostoff SW (1984) Proteins of myelin. In: Myelin, Ed 2 (Morell P, ed), pp 197-224. New York: Plenum.

Menezes JRL, Luskin MB (1994) Expression of neuron-specific tubulin defines a novel population in the proliferative layers of the developing telencephalon. J Neurosci 14:5399-5416.

Nakao J, Yamada M, Kagawa T, Kim SU, Miyao Y, Shimizu K, Mikoshiba K, Ikenaka K (1995) Expression of proteolipid protein gene is directly associated with secretion of a factor influencing oligodendrocyte development. J Neurochem 64:2396-2403.

Nixon RA (1982) Increased axonal proteolysis in myelin-deficient mutant mice. Science 215:999-1001.

Pahl HL, Baeuerle PA (1997) The ER-overload response: activation of NF- $\kappa$ B. Trends Biol Sci 22:63-67.
Readhead C, Hood L (1990) The dysmyelinating mouse mutations shiverer (shi) and myelin deficient (shi ${ }^{\text {mld }}$ ). Behav Genet 20:213-234.

Readhead C, Popko B, Takahashi N, Shine HD, Saavedra RA, Sidman RL, Hood L (1987) Expression of a myelin basic protein gene in transgenic shiverer mice: correction of the dysmyelinating phenotype. Cell 48:703-712.

Readhead C, Schneider A, Griffiths I, Nave K-A (1994) Premature arrest of myelin formation in transgenic mice with increased proteolipid protein gene dosage. Neuron 12:583-595.

Robertson AM, King RHM, Muddle JR, Thomas PK (1997) Abnormal Schwann cell/axon interactions in the Trembler-J mouse. J Anat 190:423-432.

Sinoway MP, Kitagawa K, Timsit S, Hashim GA, Colman DR (1994) Proteolipid protein interactions in transfectants: implications for myelin assembly. J Neurosci Res 37:551-562.

Snipes GJ, Orfali W (1998) Common themes in peripheral neuropathy disease genes. Cell Biol Int 22:815-835.

Stecca B, Southwood CM, Gragerov A, Kelley KA, Friedrich VL, Gow A (2000) The evolution of lipophilin genes from invertebrates to tetrapods: DM-20 cannot replace proteolipid protein in CNS myelin. J Neurosci 20:4002-4010.

Syková E, Svoboda J (1990) Extracellular alkaline-acid-alkaline transients in the rat spinal cord evoked by peripheral stimulation. Brain Res 512:181-189.

Thomson CE, Montague P, Jung M, Nave K-A, Griffiths IR (1997) Phenotypic severity of murine Plp mutants reflects in vivo and in vitro variations in transport of PLP isoproteins. Glia 20:322-332.

Ting-Beall HP, Lees MB, Robertson JD (1979) Interactions of FolchLees proteolipid apoprotein with planar lipid bilayers. J Membr Biol 51:33-46.

Witt A, Brady ST (2000) Unwrapping new layers of complexity in axon/ glial relationships. Glia 29:112-117.

Wood P, Okada E, Bunge R (1980) The use of networks of dissociated rat dorsal root ganglion neurons to induce myelination by oligodendrocytes in culture. Brain Res 196:247-252.

Wood PM, Williams AK (1984) Oligodendrocyte proliferation and CNS myelination in cultures containing dissociated embryonic neuroglia and dorsal root ganglion neurons. Dev Brain Res 12:225-241.

Xiong Z-Q, Stringer JL (2000) Regulation of extracellular $\mathrm{pH}$ in the developing hippocampus. Dev Brain Res 122:113-117.

Yamada M, Ivanova A, Yamaguchi Y, Lees MB, Ikenaka K (1999) Proteolipid protein gene product can be secreted and exhibit biological activity during early development. J Neurosci 19:2143-2151.

Yamaguchi Y, Ikenaka K, Niinobe M, Yamada H, Mikoshiba K (1996) Myelin proteolipid protein (PLP), but not DM-20, is an inositol hexakisphosphate-binding protein. J Biol Chem 271:27838-27846.

Yang X, Skoff RP (1997) Proteolipid protein regulates the survival and differentiation of oligodendrocytes. J Neurosci 17:2056-2070.

Yoshida M, Colman DR (1996) Parallel evolution and coexpression of the proteolipid proteins and protein zero in vertebrate myelin. Neuron 16:1115-1126. 